Article

\title{
Peukert Revisited-Critical Appraisal and Need for Modification for Lithium-Ion Batteries
}

\section{Noshin Omar *, Peter Van den Bossche, Thierry Coosemans and Joeri Van Mierlo}

Mobility, Logistics and Automotive Technology Research Centre (MOBI), Vrije Universiteit Brussel, Pleinlaan 2, Brussel 1050, Belgium; E-Mails: pvdbos@vub.ac.be (P.V.B.); thierry.coosemans@vub.ac.be (T.C.); jvmierlo@vub.ac.be (J.V.M.)

* Author to whom correspondence should be addressed; E-Mail: noshomar@vub.ac.be; Tel.: +32-2-5591512.

Received: 15 August 2013; in revised form: 3 October 2013 / Accepted: 9 October 2013 / Published: 25 October 2013

\begin{abstract}
The Peukert relationship was originally introduced in 1897 for lead-acid batteries and defines one of the most common parameters for battery performance evaluation. This article assesses its application for lithium-ion batteries. From the performed analysis, we can conclude that the Peukert relationship is suitable in a narrow working range such as limited current range and almost constant working temperature. Taking into account however that lithium-ion traction batteries in battery electric vehicle applications operate under strongly variable conditions, a novel relationship has been developed, allowing a more accurate description of the discharge capacity of lithium-ion batteries than the Peukert relationship does. The proposed new relationship has been derived based on comprehensive experimental analysis of the parameters that affect the battery discharge capacity and can be implemented in battery mathematical models.
\end{abstract}

Keywords: lithium-ion; Peukert relationship; discharge capacity

\section{Introduction}

Since the beginning of the automobile era, the internal combustion engine (ICE) has been used for vehicular propulsion. However, motor vehicles powered by the ICE are significant contributors to air pollutants and greenhouse gases linked to global climate change [1,2]. As the global economy begins to strain under the pressure of rising petroleum prices and environmental concerns, researchers have 
spurred the development of various types of clean energy transportation systems such as hybrid electric vehicles (HEVs), battery electric vehicles (BEVs) and plug-in hybrid electric vehicles (PHEVs) [3-5]. In urban traffic, due to their beneficial effect on the environment, electric vehicles are an important factor for improvement of traffic and more particularly for a healthier living environment. However, for an adequate battery management, such vehicles require a well defined accurate battery model on the cell level as well as on the pack level, which is able to predict the battery behavior during transient and steady state events. Furthermore, the model should be equipped with a precise state of charge (SoC) estimation method, because of the dependency of all battery model parameters on this factor.

During the last years, many estimation methods have been developed and proposed. The generally known relationship states the $\mathrm{SoC}$ as a function of the open circuit voltage [6]. However, this method is not suitable for all battery chemistries. Especially, for lithium iron phosphate (LFP) batteries, which show a flat discharge characteristic between $90 \%$ and $10 \% \mathrm{SoC}$ as presented in Figure 1, the voltage does not allow an accurate estimation of the SoC [7].

Figure 1. Voltage evolution of lithium iron phosphate (LFP) based battery $(2.3 \mathrm{~A} \mathrm{~h})$ at $25^{\circ} \mathrm{C}$.

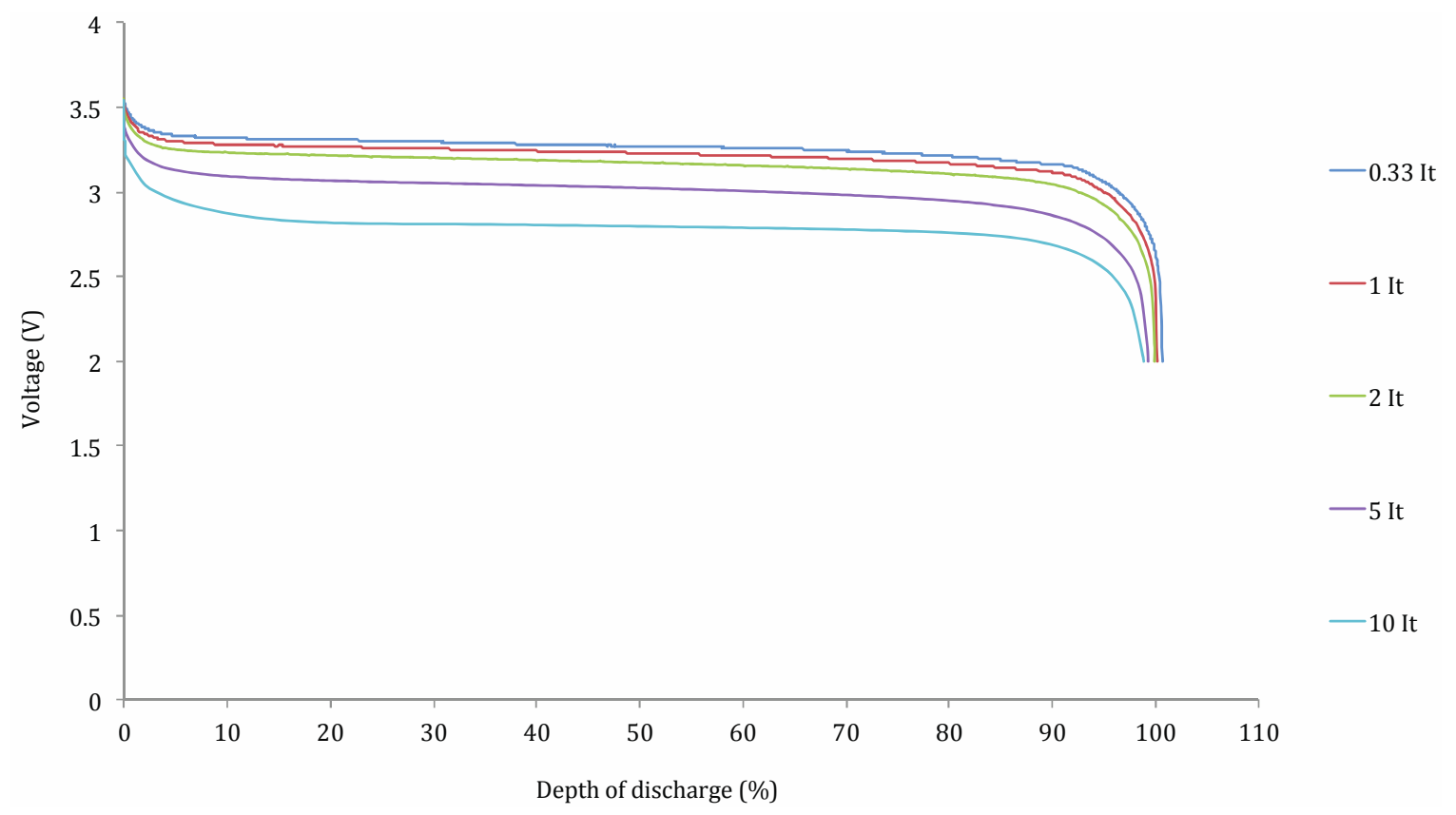

Other methods have been studied such as Kalman Filtering and Fuzzy Logic [8-15].

Han et al. [16] proposed an adaptive Kalman Filter for estimation of SoC. Then, He et al. [17] developed a SoC methodology based on the open circuit voltage (OCV) in the vehicle. In this work, intrinsic relationships between $\mathrm{OCV}$ and SoC have been derived and implemented by a recursive least squares (RLS) algorithm with an optimal forgetting factor.

Further, He et al. [18] introduced unscented Kalman filtering for an accurate estimation of SoC. According to simulation and experimental results, the error percentage is less than $4 \%$.

In order to improve the accuracy of the SoC calculation, Cho et al. [19] developed a methodology based on OCV-SoC under different operating conditions. In this work, an electrochemical model and a recursive estimator have been used for the battery, but these techniques are very complicated and need powerful processing systems. 
Another approach has been proposed for estimation of SoC [20]. The method is mainly based on ampere-hour counting. However, an accurate prediction of the battery capacity is strongly depending of the Peukert constant as presented by Equation (1) [21]:

$$
C_{d i s}=T_{d i s} \cdot I_{d i s}^{k}
$$

where $C_{d i s}$ represents the discharge capacity in $(\mathrm{A} \mathrm{h})$; and $T_{d i s}$ and $I_{d i s}$ are the discharge time and discharge current expressed in (s) and (A), respectively. The parameter $k$ is the Peukert constant. This parameter is strongly dependent on the battery technology. For lead-acid batteries, the factor $k$ varies between 1.1 and 1.3.

The Peukert equation is an empirical relationship describing the battery discharge capacity. When the Peukert constant is equal to 1 , the discharge capacity will be independent of the applied current. When $k$ is higher than 1 , the discharge capacity will decrease.

However, for lithium-ion technology this parameter changes between 1.00 and 1.28, as presented in Figure 2, whereby the Peukert constant of several lithium-ion batteries having different cell designs, chemistries and capacities have been calculated based on $1 I_{t}$ and $2 I_{t}$ current rates and at room temperature.

The notation $I_{t}$ represents the current rate as documented in the standard IEC 61434 [22] and presented by Equation (2):

$$
I_{t}=\frac{C}{1 h}
$$

Figure 2. Peukert constant of several lithium-ion batteries having different cell design, chemistries and capacities.

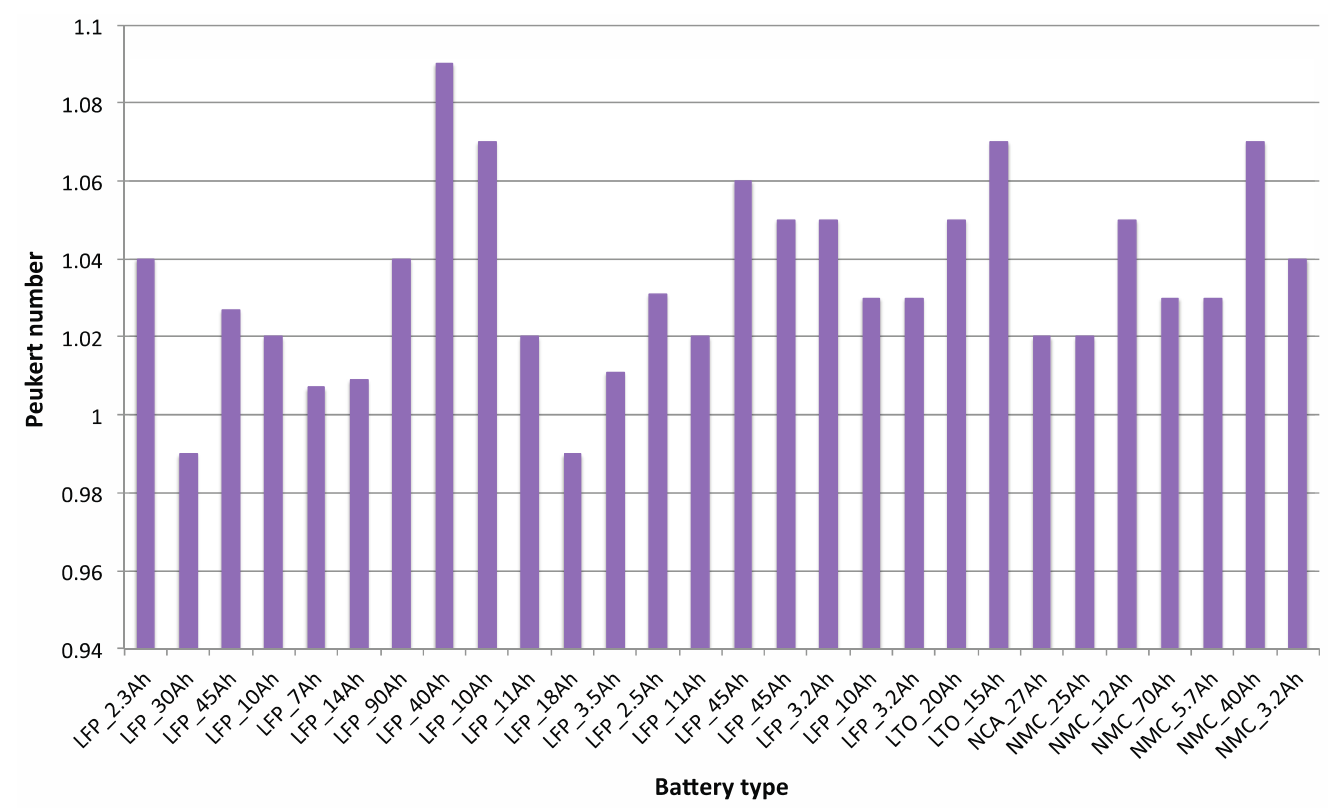

Doerfell et al. [23] examined the Peukert phenomenon for different lead-acid batteries. They found that the Peukert law should be interpreted very carefully, and concluded that the relationship is only valid if the discharge current is constant and the temperature increase inside the battery is limited.

In [24], the Peukert relationship has been simulated from the electrochemical point of view. In this reference, three rate dependent parameters have been investigated (specific active surface area, tortuosity exponent of the electrode morphology and the maximum capacity density). The authors 
concluded that at high current rates, an exhaustion of sulfuric acid may occur in the positive plate as a result of acid transport limitation. The main factor that determines the end of discharge behavior is the change of the active surface area, which is underpinned by the clogging of the pores due to sulfation of the electrode [24]. Here it should be noted that the investigation was only limited to lead-acid technology.

In [7], it is reported that the SoC easily can be determined by using the Ampère-hour accounting. This equation contains the well-known Peukert constant. The determination of SoC based on the Ampère-hour can be accurate if the assumption of the Peukert constant is correct. In the literature, the Peukert factor is assumed to be a constant. However, the performed analysis indicates that the SoC according to the mentioned method could be estimated accurately if all parameters, which affect the Peukert constant and the battery discharge capacity, will be taken into account.

Therefore, in this article a critical analysis of several parameters that affect the Peukert constant has been carried out. Since several lithium-ion chemistries exist, there is a need to perform such analysis on various lithium-ion types and chemistries.

\section{Methodology}

In order to examine the Peukert relationship in depth, the performances of four lithium-ion battery chemistries as presented in Table 1 , have been investigated at various working temperatures $\left(-18^{\circ} \mathrm{C}\right.$, $0{ }^{\circ} \mathrm{C}, 25^{\circ} \mathrm{C}$ and $\left.40{ }^{\circ} \mathrm{C}\right)$ and at different current rates $\left(0.3 I_{t}, 1 I_{t}, 2 I_{t}, 5 I_{t}\right.$ and $\left.10 I_{t}\right)$, using a SBT 0550 battery tester SBT 0550 from the company PEC (Leuven, Belgium) and a climate chamber from CTS (Ninove, Belgium) [25].

Table 1. Specifications tested battery cells.

\begin{tabular}{cccc}
\hline Chemistry & Capacity (A h) & Voltage (V) & Shape \\
\hline Lithium iron phosphate (LFP) & 2.3 & 3.3 & Cylindrical \\
Lithium nickel manganese cobalt (NMC) & 40 & 3.7 & Pouch \\
Lithium nickel cobalt aluminum (NCA) & 27 & 3.7 & Cylindrical \\
Lithium titanate (LTO) & 15 & 2.2 & Pouch \\
\hline
\end{tabular}

\section{Results and Discussion}

Capacity Tests at Different Working Temperatures

Lithium Nickel Manganese Cobalt Oxide (NMC)

Figures 3-17 illustrate a comparison of the discharge characteristics of the four proposed battery chemistries as presented in Table 1. From Figure 3, we observe that the NMC cathode battery has particularly good performance in terms of delivered capacity in the envelope $0.33 I_{t}$ and $2 I_{t}$ and in the temperature range of $25{ }^{\circ} \mathrm{C}$ to $40{ }^{\circ} \mathrm{C}$. Here it should be noted that the normalized discharge capacity starting from current rate $3 I_{t}$ in Figure 3 at $40{ }^{\circ} \mathrm{C}$ is less than at $25{ }^{\circ} \mathrm{C}$. At high current rates, the heat generation becomes significant and therefore the cell temperature reaches the maximum allowed temperature $\left(50^{\circ} \mathrm{C}\right)$. Under these conditions, the discharge regime ends and therefore, the discharge capacity is lower than at $25^{\circ} \mathrm{C}$. 
Figure 3 indicates that the performance of the battery is lower at high current rates $\left(5 I_{t}\right)$, which is due to the fact that the battery has been designed to deliver sufficient capacity up to $2 I_{t}$. Its low temperature characteristics (Figure 3) are rather poor however, with the normalized capacity decreasing from $100 \%$ at $25{ }^{\circ} \mathrm{C}$ to $57 \%$ at $-18^{\circ} \mathrm{C}$ for the same current rate $\left(1 I_{t}\right)$.

Figure 3. Normalized discharge capacity for a lithium nickel manganese cobalt (NMC) battery cell at various temperatures and current rates.

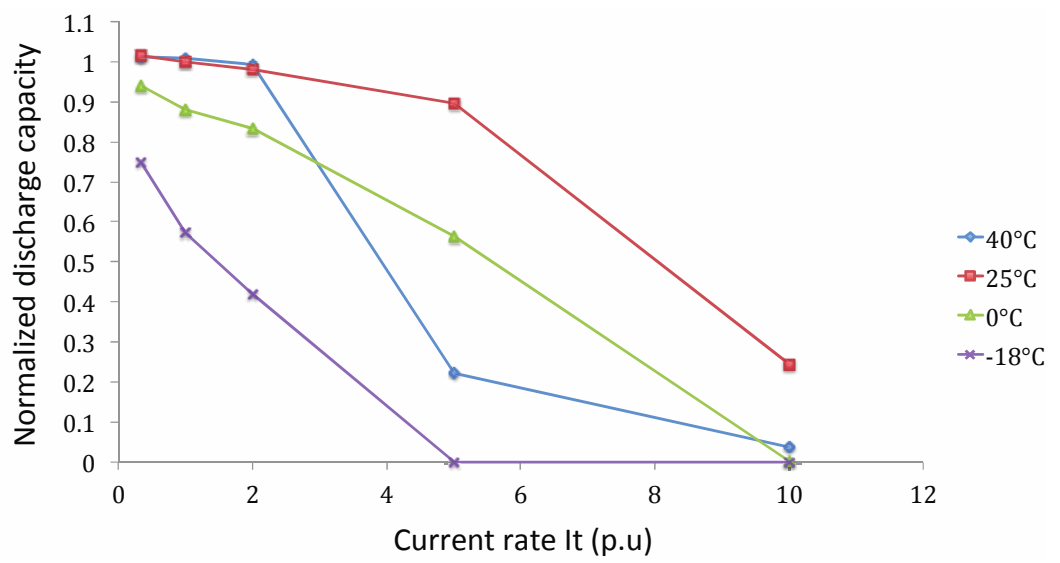

The normalized capacity parameter as presented by Equation (3) has been introduced in this article in order to represent the ratio of the discharge capacity and the reference capacity $\left(1 I_{t}\right.$ at $\left.25^{\circ} \mathrm{C}\right)$ :

$$
C_{\text {norm }}=\frac{C_{n, t^{\circ}}}{C_{1 I_{t}, 25^{\circ} \mathrm{C}}}
$$

where:

- $C_{\text {norm }}$ : normalized discharge capacity;

- $C_{n, t^{\circ}}$ : discharge capacity at current rate $n$ and working temperature $t^{\circ}(\mathrm{A} \mathrm{h})$;

- $C_{1 I t, 25^{\circ} \mathrm{C}}$ : discharge capacity at $1 I_{t}$ current rate and $25^{\circ} \mathrm{C}(\mathrm{A} \mathrm{h})$.

This point is also obvious in Figure 4, where the Peukert relationship is featured by time and current. As mentioned before, the characteristic relationship in Figure 4 should be linear when the Peukert number is equal to 1 . However, Figure 4 shows that this property cannot be achieved at low temperature and high current rates.

Figure 4. Peukert plot at different temperatures (NMC) and currents.

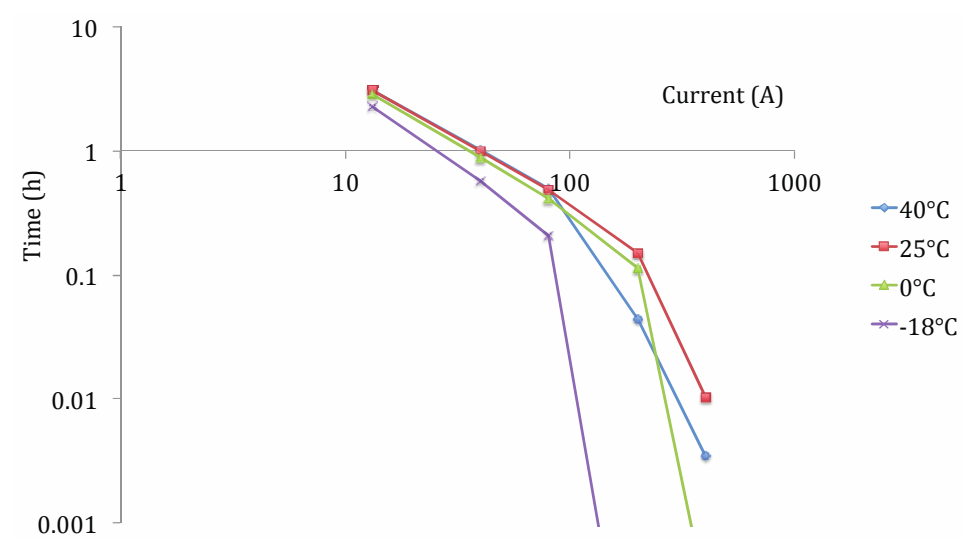


The voltage curves in Figure 5 indicate that at low temperatures the voltage drop due to the ohmic resistance increases. In [7,26,27], it is documented that this characteristic is related to the increase of the electrolyte resistance. Therefore, the range of a PHEV in the electric mode at high currents and low temperatures will be considerably lower compared to at room temperature. From this analysis, we observe that a battery is a complex system, where the capacity is a function of current rate, depth of discharge and temperature. In order to represent these parameters by a mathematical relationship, in this paper the differential Equation (4) is proposed:

$$
C_{d i s, I, t^{\circ}, D o D}=\left[\frac{C_{d i s}}{\partial I_{d i s}} C_{d i s, I}+\frac{\partial C_{d i s}}{\partial t^{\circ}} C_{d i s, t^{\circ}}+\frac{\partial C_{d i s}}{\partial D o D} C_{d i s, D o D}\right]+C^{\text {cte }}
$$

where:

- $C_{d i s}$ : discharge capacity (A h);

- $D o D$ : depth of discharge (\%);

- $t^{\circ}$ : operating temperature $\left({ }^{\circ} \mathrm{C}\right)$;

- $I_{\text {dis }}$ : applied current (A);

- $\mathrm{C}^{\text {cte }}:$ a constant.

Here one can observe that this relationship has been linearized at each operating point. However, the impact of the mutual relationships between the parameters on the discharge capacity of the battery, which may be able to predict the battery discharge capacity more accurately than the classical Peukert relationship, is not considered in this analysis.

Figure 5. Voltage and temperature behaviour of NMC battery cell at $0{ }^{\circ} \mathrm{C}$ working temperature and current rates [here it should be noted that the temperature and voltage evolutions at $10 I_{t}$ are not visible due to the immediately voltage drop under the minimum voltage as specified by the battery manufacturer $(3 \mathrm{~V})]$.

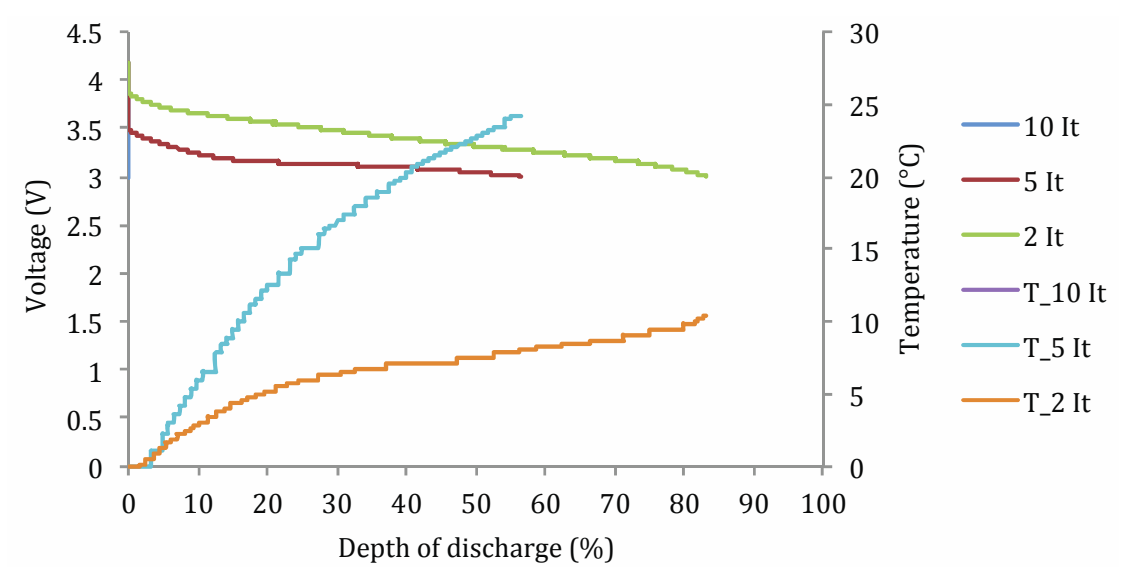

Lithium Iron Phosphate (LFP)

Figure 6 shows the favorable performance of the LFP battery against the NMC one over the whole working temperature range and current rates. Especially at $0{ }^{\circ} \mathrm{C}$, the LFP-based battery demonstrates excellent performances due to the self-heating mechanism that occurs at high current rates. 
Figure 6. Normalized discharge capacity for LFP battery cell at various working temperatures and current rates.

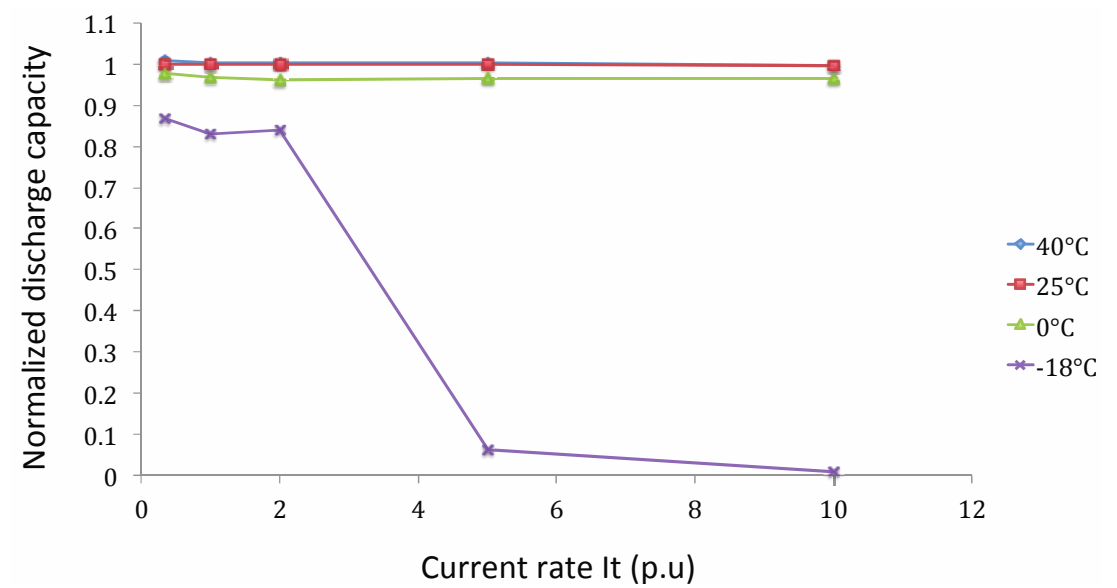

Here, it is notable that the Peukert number in the temperature range $\left(0^{\circ} \mathrm{C}\right.$ to $\left.40{ }^{\circ} \mathrm{C}\right)$ is close to 1 , as demonstrated in Figure 7.

Figure 7. Peukert plot at different temperatures and current rates (LFP).

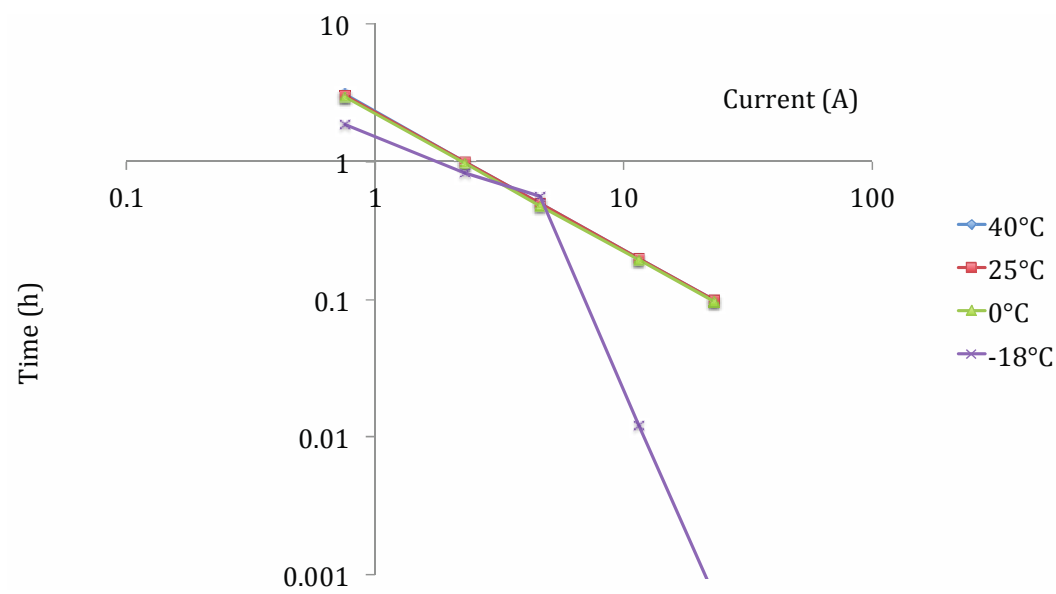

In Figure 8, we observe that the voltage at $10 I_{t}$ drops close to the minimal voltage $(2 \mathrm{~V})$, but still remains above $2 \mathrm{~V}$. Then, the voltage recovers when the battery temperature increases considerably $\left(43{ }^{\circ} \mathrm{C}\right)$ due to the Joule heating. The battery is able to attain almost the same discharge capacity as at lower current rates and high working temperature. The physical appearance of self-heating is due to the higher internal resistance [7].

However, at low temperatures $\left(-18{ }^{\circ} \mathrm{C}\right.$ and below) the Peukert number increases to an extremely high value of 1.85 due to the reduced discharge capacity, which is caused by the significant raise in internal resistance. It should be pointed out that in the region $0.33 I_{t}$ and $2 I_{t}$, the Peukert number is smaller than 1 , which is in contradiction with the Peukert equation. This equation, defined principally for lead-acid batteries at relatively low current rates and at operating temperatures close to the room temperature, is in fact not sufficient for describing lithium-ion batteries mainly at low temperatures $\left(-18^{\circ} \mathrm{C}\right)$, since non-linear phenomena occur there. 
Figure 8. Voltage and temperature behavior of LFP battery cell at $0{ }^{\circ} \mathrm{C}$ working temperature and current rates.

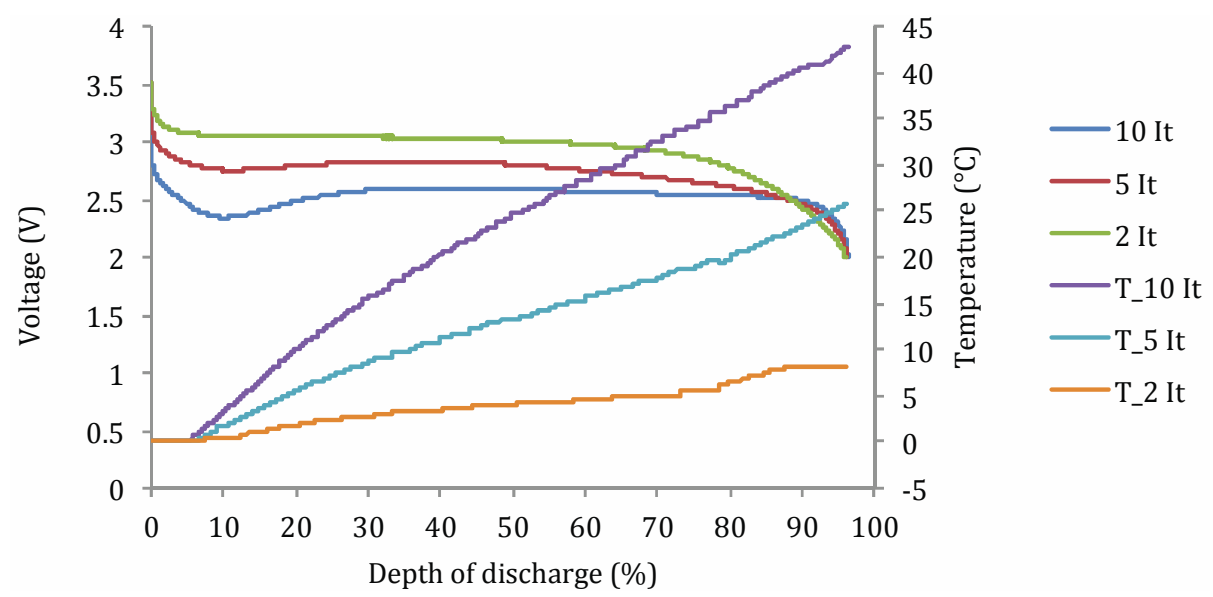

However, the working temperature has not only an impact on the capacity of the battery. It seems also that it influences the energy density of the battery. Since in real operation the battery is subject to variable current rates, the above investigation has been extended, whereby the energy density has been calculated at different working temperatures and current rates.

In Figure 9, the energy density varies significantly from the results as indicated in [7], $82 \mathrm{~W} \mathrm{~h} / \mathrm{kg}$ against $106 \mathrm{~W} \mathrm{h/kg}$. The best energy density values are obtained at high temperatures and low current rates.

Figure 9. Energy density at different current rates and working temperatures (LFP).

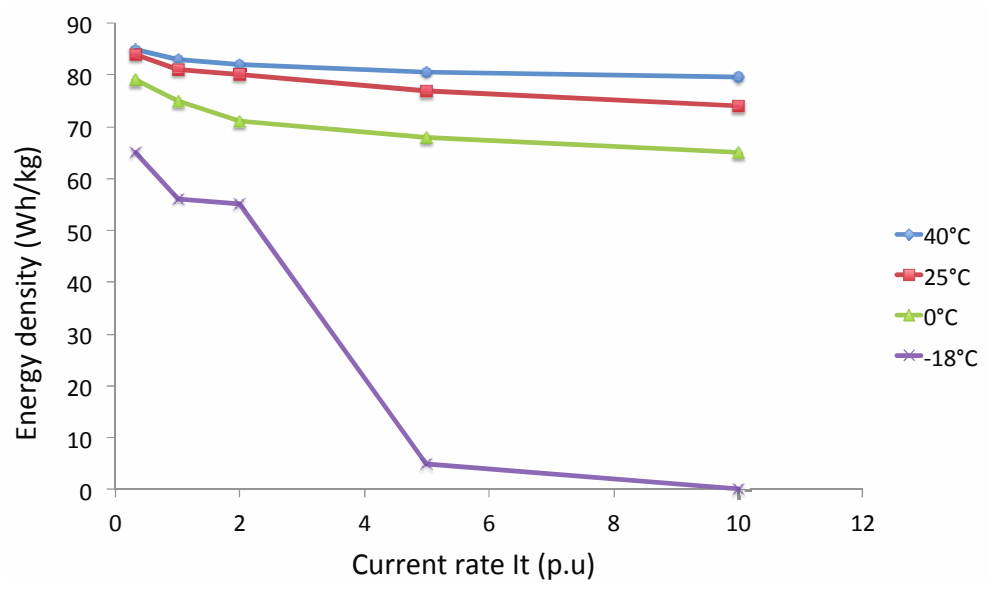

In contrast to reference [7], the energy relation as a function of current at $40{ }^{\circ} \mathrm{C}$ and $25{ }^{\circ} \mathrm{C}$ is linear, while the relation at $0{ }^{\circ} \mathrm{C}$ is more logarithmical as presented by Equation (5). At $-18{ }^{\circ} \mathrm{C}$, the energy density evolution is more non-linear, which is very hard to predict based on relationships such as Peukert:

$$
\rho_{\text {den }}=\alpha \cdot \ln \left[\frac{I_{d i s}}{I_{t}}\right]+b
$$

where:

- $\rho_{\text {den }}$ : energy density $(\mathrm{W} \mathrm{h} / \mathrm{kg})$;

- I: applied current (A); 
- $a$ and $b$ : coefficient $(\mathrm{W} \mathrm{h} / \mathrm{kg})$;

- $I_{t}$ : reference current $(\mathrm{A})$.

The voltage curves at $1 I_{t}$ at different working temperatures (see Figure 10) show that the mean voltage decreases at lower temperatures. This lower voltage will also affect the whole performance of the battery at low temperatures.

Figure 10. Effect of LFP cell temperature on discharge voltage and capacity (cell were discharged at $\left.1 I_{t}\right)$.

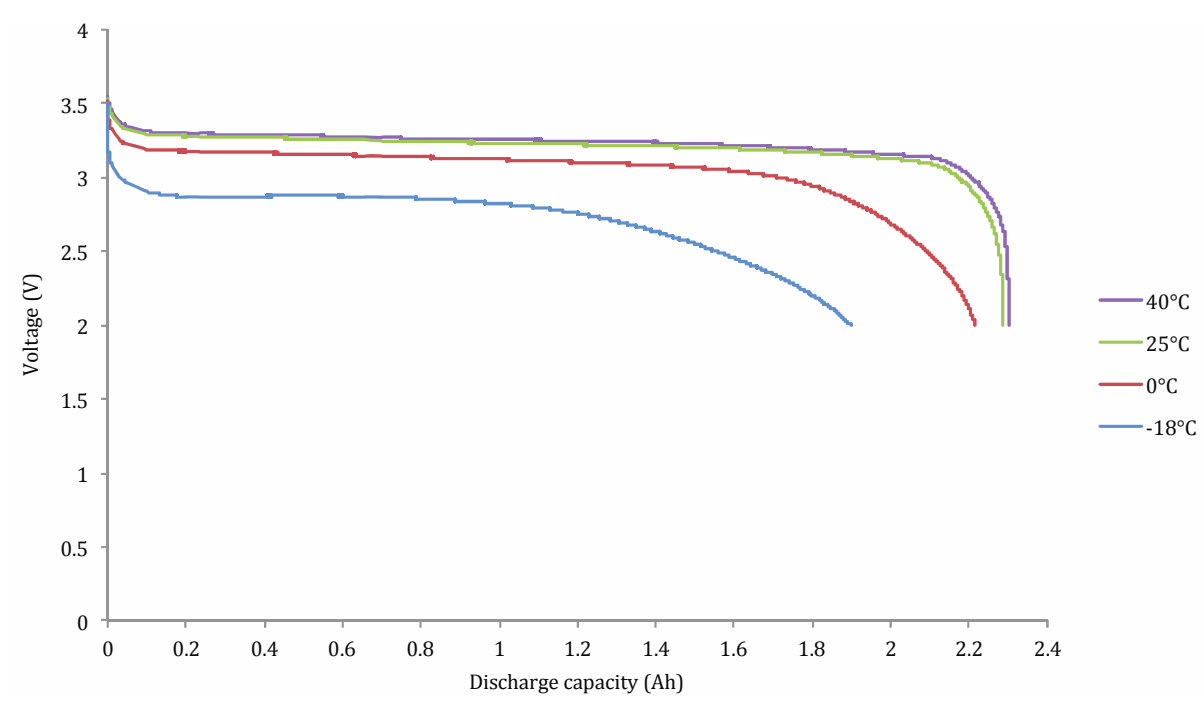

Another non-linear behavior of the battery is illustrated in Figure 11. As we can observe the battery voltage does not achieve the same level after finishing the discharge process. In Figure 11, it is noticeable that the increase of the voltage at higher discharge current rates is higher when the voltage is stabilized at $\mathrm{U}_{2}$. This means that the battery still is able to provide more capacity but at more lower current.

Figure 11. Voltage response after achieving the minimum battery voltage at $25^{\circ} \mathrm{C}$.

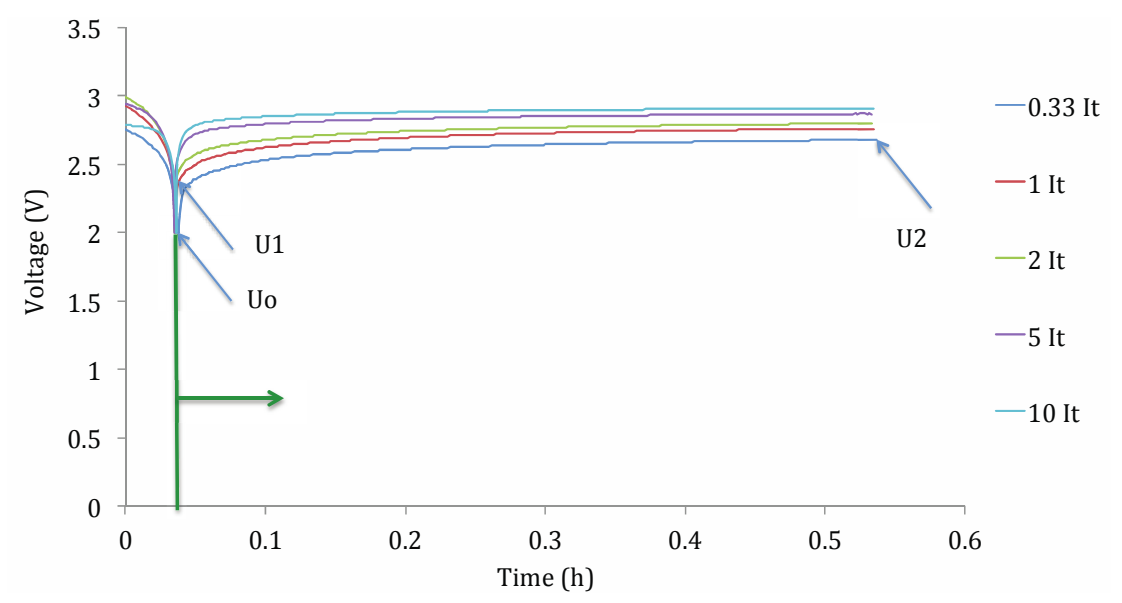

In Table 2, one can observe that the battery is still able to provide more capacity at lower current rates. 
Table 2. Discharge capacity at $0.5 I_{t}$ when the battery voltage was stabilized after 40 min at LFP 2.3 A h battery type.

\begin{tabular}{cccc}
\hline $\begin{array}{c}\text { Current rate } \\
\boldsymbol{I}_{\boldsymbol{t}}(\mathbf{A})\end{array}$ & $\begin{array}{c}\text { Discharge capacity } \\
\mathbf{a t} \mathbf{4 0}{ }^{\circ} \mathbf{C} \mathbf{( A ~ h )}\end{array}$ & $\begin{array}{c}\text { Discharge capacity } \\
\text { at } \mathbf{2 5}{ }^{\circ} \mathbf{C}(\mathbf{A ~ h})\end{array}$ & $\begin{array}{c}\text { Discharge capacity } \\
\text { at } \mathbf{~ 1 0}{ }^{\circ} \mathbf{C}(\mathbf{A ~ h})\end{array}$ \\
\hline 0.33 & 0.220 & 0.200 & 0.189 \\
1 & 0.220 & 0.210 & 0.195 \\
2 & 0.240 & 0.230 & 0.200 \\
3 & 0.242 & 0.232 & 0.225 \\
5 & 0.244 & 0.237 & 0.227 \\
10 & 0.245 & 0.242 & 0.229 \\
\hline
\end{tabular}

Then, Table 3 illustrates that the duration of the rest time has an impact on the provided discharge capacity. This aspect confirms the various drawbacks of the traditional Peukert relationship.

Table 3. Discharge capacity at $0.5 I_{t}$ when the battery voltage was stabilized after $15 \mathrm{~min}$ at LFP 2.3 A h battery type.

\begin{tabular}{cccc}
\hline $\begin{array}{c}\text { Current rate } \\
\boldsymbol{I}_{\boldsymbol{t}} \mathbf{( A )}\end{array}$ & $\begin{array}{c}\text { Discharge capacity } \\
\text { at } \mathbf{4 0}{ }^{\circ} \mathbf{C}(\mathbf{A ~ h})\end{array}$ & $\begin{array}{c}\text { Discharge capacity } \\
\text { at } \mathbf{2 5}{ }^{\circ} \mathbf{C}(\mathbf{A ~ h})\end{array}$ & $\begin{array}{c}\text { Discharge capacity } \\
\text { at } \mathbf{~ 1 0}{ }^{\circ} \mathbf{C}(\mathbf{A ~ h})\end{array}$ \\
\hline 0.33 & 0.200 & 0.188 & 0.185 \\
1 & 0.205 & 0.195 & 0.192 \\
2 & 0.215 & 0.220 & 0.198 \\
3 & 0.225 & 0.225 & 0.210 \\
5 & 0.228 & 0.232 & 0.22 \\
10 & 0.235 & 0.238 & 0.225 \\
\hline
\end{tabular}

Lithium Nickel Cobalt Aluminum Oxide (NCA)

In Figure 12, an overview of the results for NCA cathode batteries are presented. In contradiction with the NMC battery, the NCA based battery shows good abilities in the temperature range of $0{ }^{\circ} \mathrm{C}$ to $40{ }^{\circ} \mathrm{C}$ and as well as at higher current rates, but behaves poorly at $-18{ }^{\circ} \mathrm{C}$ and high current rates, so therefore a heating system at this working temperature is recommended.

Figure 13 illustrates that the self-heating mechanism is responsible for the relative high capacity that can be achieved by employing a current rate of $10 I_{t}$, where the battery temperature is raising from $0{ }^{\circ} \mathrm{C}$ to $43{ }^{\circ} \mathrm{C}$.

In Figure 14, a summary of the capabilities of this battery chemistry at different working temperatures is presented. As we observe, the Peukert number is almost around 1 in the temperature range $25^{\circ} \mathrm{C}$ to $40{ }^{\circ} \mathrm{C}$. However, the situation at $0{ }^{\circ} \mathrm{C}$ and below is comparable with what we have observed for the previous battery chemistry. The Peukert evolution starts in a linear way, but the curve shows an offset. From this point, the Peukert number increases significantly. 
Figure 12. Normalized discharge capacity for lithium nickel cobalt aluminum oxide (NCA) battery cell at various working temperatures and current rates.

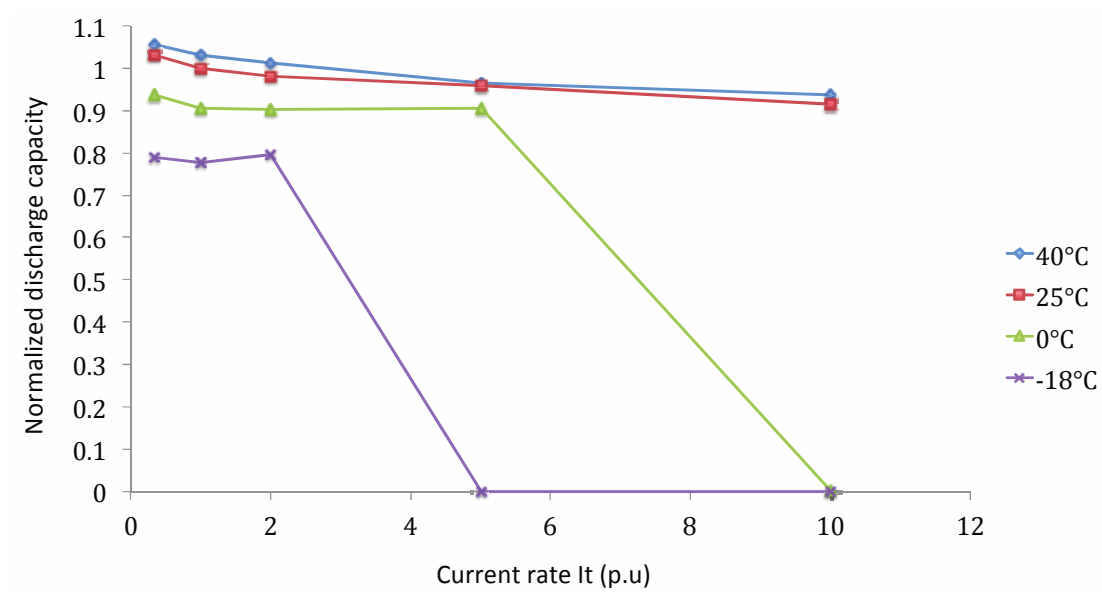

Figure 13. Voltage and temperature behaviour of NCA battery cell at $0{ }^{\circ} \mathrm{C}$ working temperature and current rates [here it should be noted that the temperature and voltage evolutions at $10 \mathrm{It}$ are not visible due to the immediately voltage drop under the minimum voltage as specified by the battery manufacturer $(2.7 \mathrm{~V})]$.

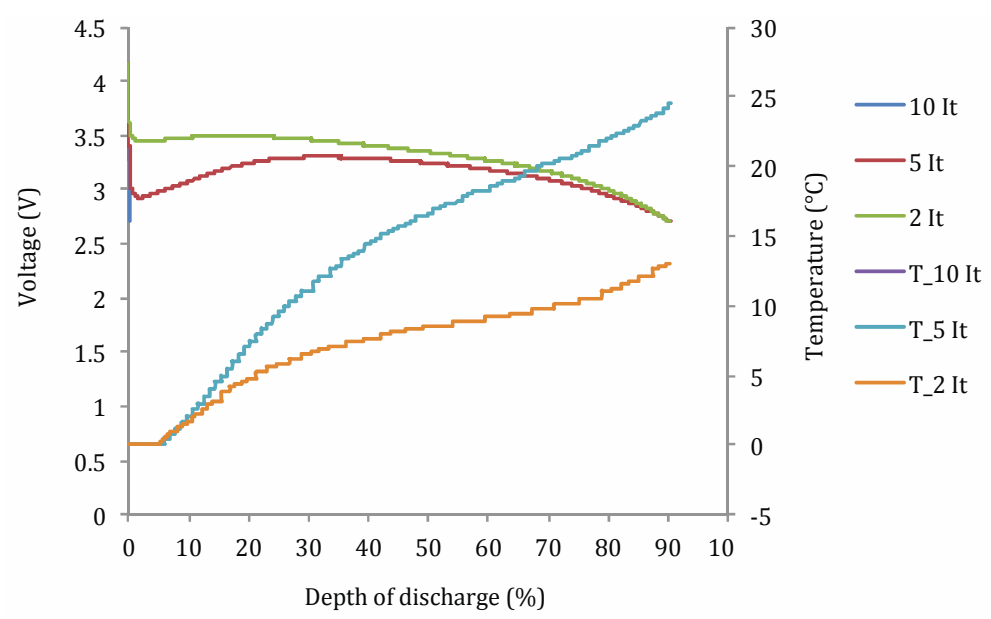

Figure 14. Peukert plot at different temperatures and currents (NCA).

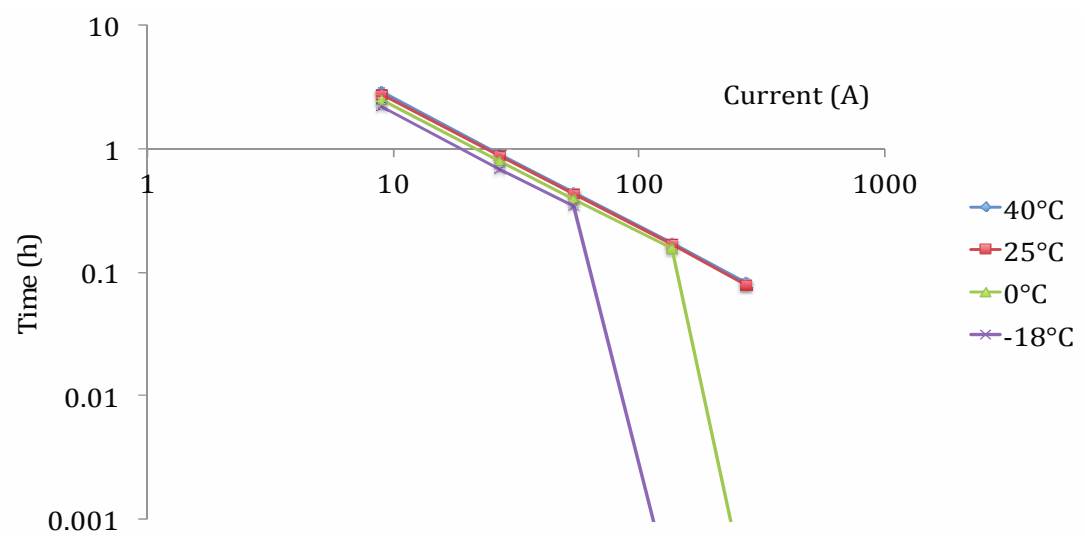


Here it should be noted that the temperature evolution at $10 I_{t}$ in Figure 13 is not visible due to the immediately voltage drop under the minimum voltage as specified by the battery manufacturer $(2.7 \mathrm{~V})$.

Lithium Titanate (LTO)

In Figure 15, an overview of the same tests given is given for the LTO cell. It is clear that LTO cells have better performances than the other studied chemistries, particularly at low temperatures. Unlike the LFP based battery, the evolution of the capacity at all working temperatures is logarithmical as presented by Equation (6):

$$
C_{\text {norm }}=c \cdot \ln \left[\frac{I_{d i s}}{I_{t}}\right]+d
$$

where:

- $C_{\text {norm: }}$ normalized capacity;

- $c$ and $d$ : coefficient.

With respect to battery modeling, prediction of performances of LTO batteries seems less complicated.

Figure 15. Normalized discharge capacity for lithium titanate (LTO) battery cell at various working temperatures and current rates.

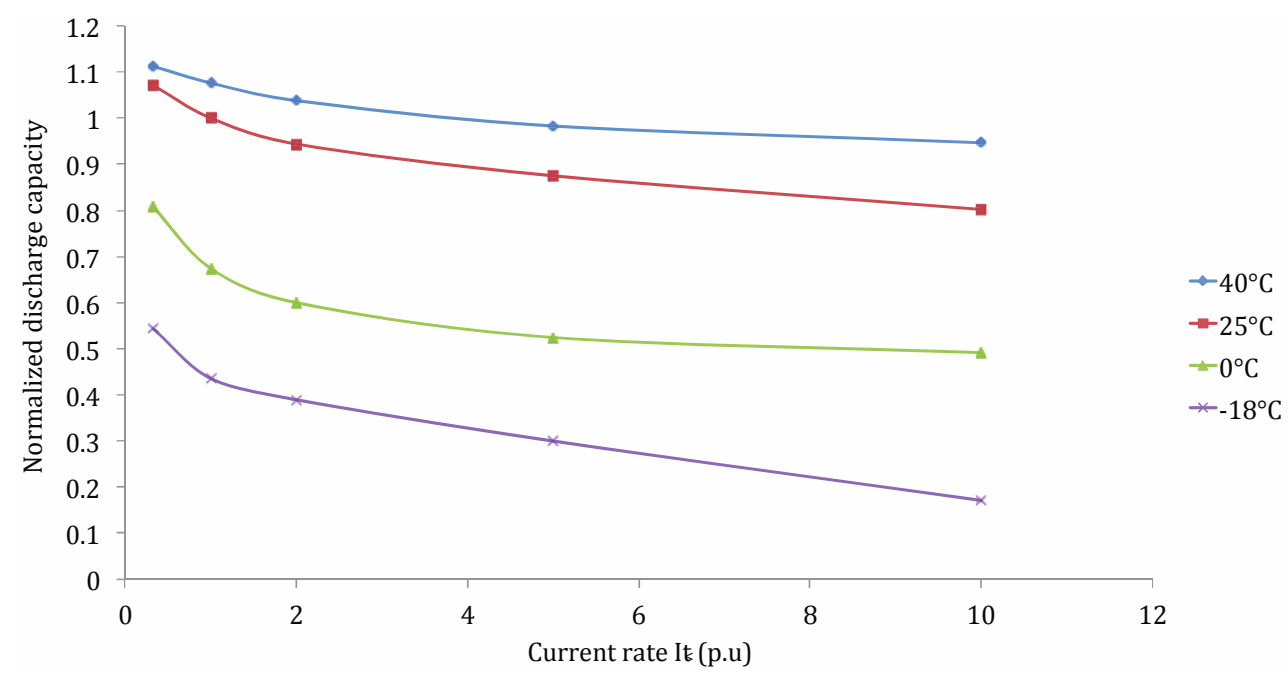

In Figure 16, the temperature increase is less pronounced than for the LFP battery.

Finally, Figure 17 shows the results of the Peukert relationship. Unlike the other chemistries, here we observe that the relationship is linear, with the Peukert number increasing with raising temperature. It is reported that the surface area of the anode in LTO batteries is 100 times larger than graphite, which results in a reduction in the internal resistance and increase of the power capabilities of the LTO battery [7]. 
Figure 16. Voltage and temperature behavior of LTO battery cell at $0{ }^{\circ} \mathrm{C}$ working temperature and current rates.

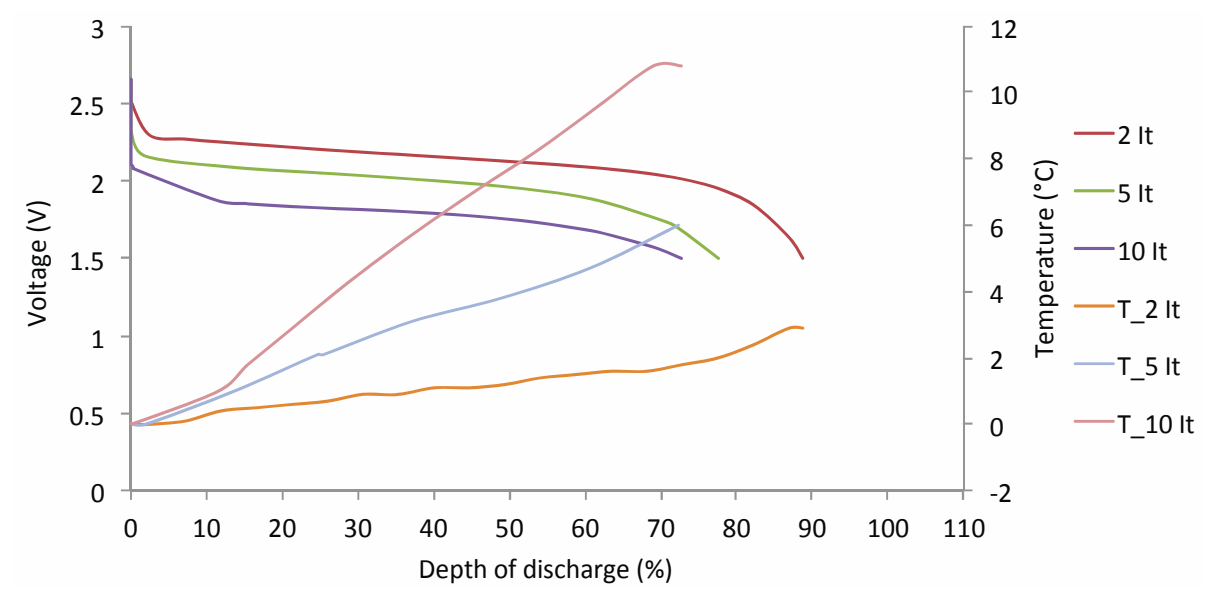

Figure 17. Peukert plot at different temperatures and currents (LTO).

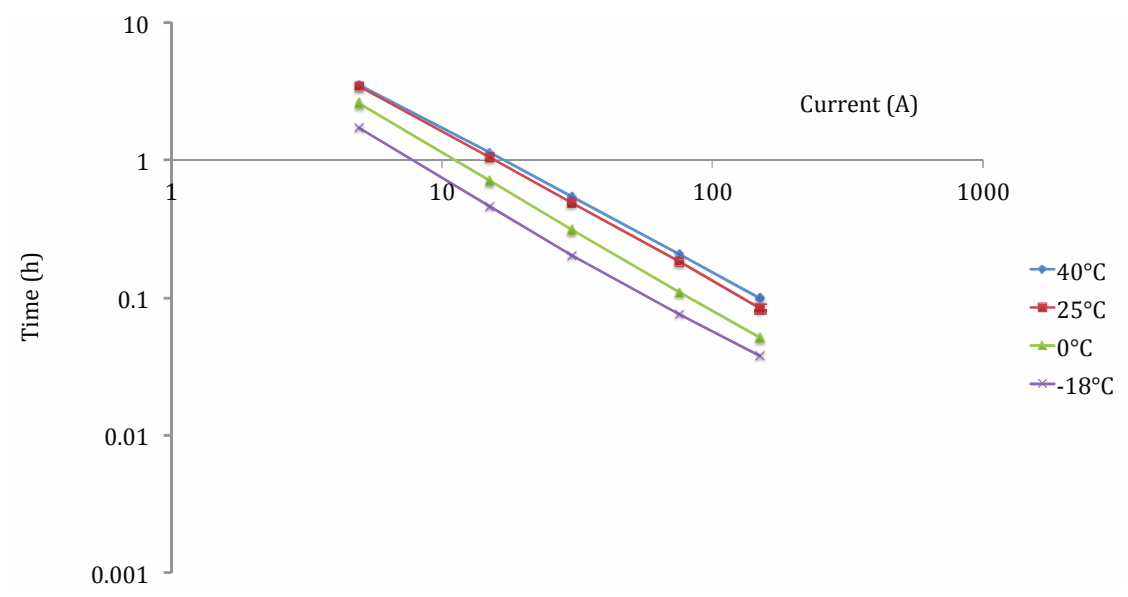

The Modified Peukert

In the field of battery characterization and modeling, the Peukert equation can be considered as a polynomial relationship. Initially derived for various lead-acid batteries at relatively low current rates and room temperature based on a statistical approach, it has shown some drawbacks for the modeling of lithium-ion batteries when discharged at high currents and low temperatures. The present form of the Peukert equation includes only the current rate as the major parameter, whereas we have observed that the temperature also has a notable impact. Furthermore, the equation assumes that the Peukert number $k$ is constant for a given battery.

Results for the LFP battery cell as presented in Figure 18 reveals that Peukert number is not an unambiguous value, but rather varies as a function of temperature and current ratio.

In Figures 18 and 19, two situations are proposed whereby the current ratio varies. 
Figure 18. Peukert change versus current rate ratio (scenario 1) at room temperature for LFP battery.

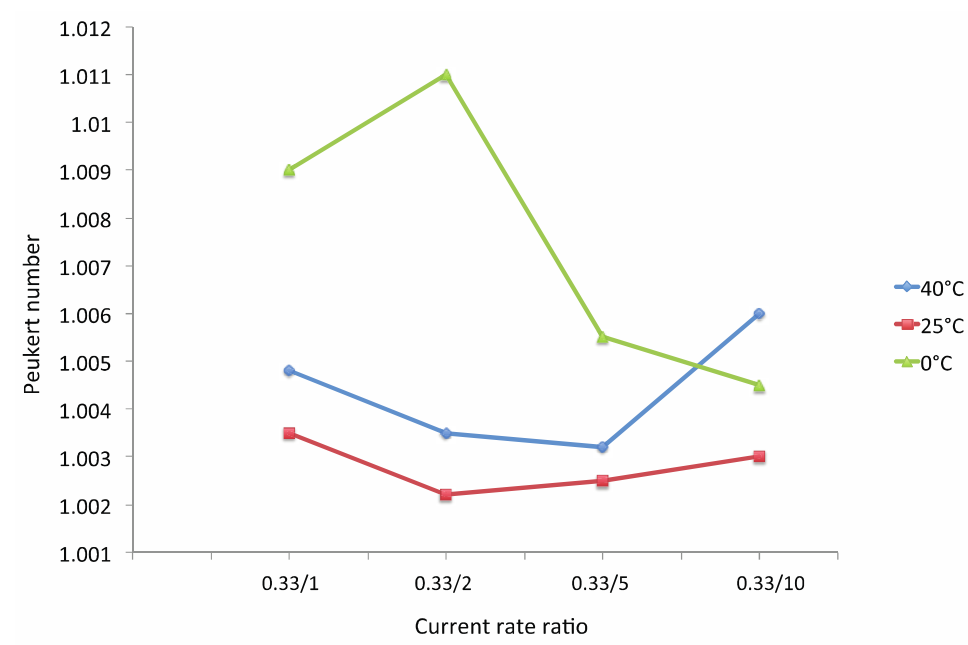

Figure 19. Peukert change versus current rate ratio (scenario 2) at room temperature for LFP battery.

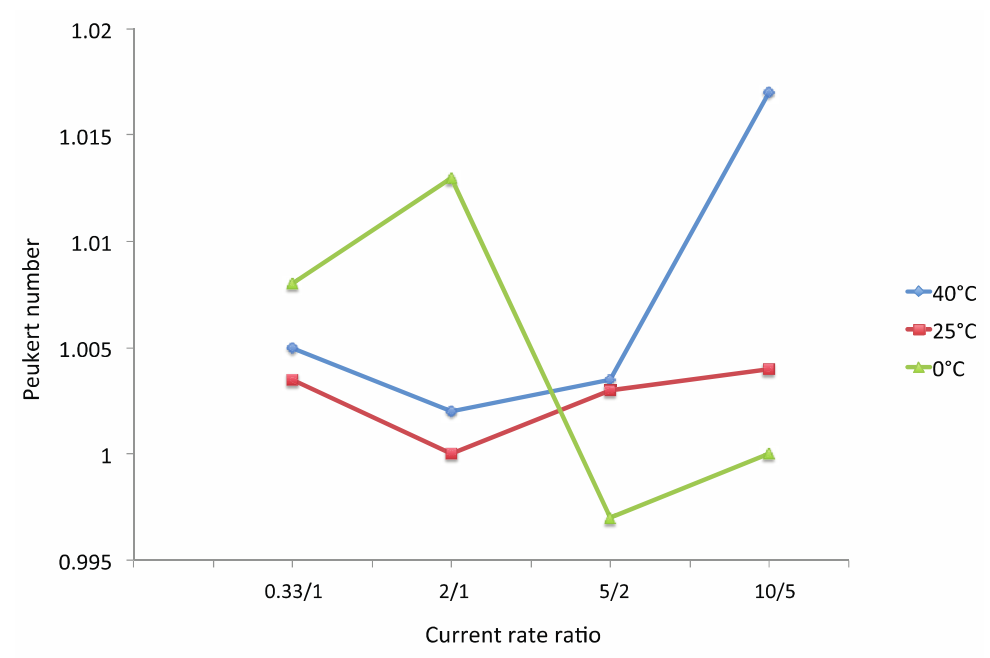

The situation becomes more complex when taking into account battery ageing, with the Peukert number increasing the more the battery is cycling (as illustrated in Figure 20).

The Peukert equation in the present form is not sufficient to predict the discharge capacity of lithium-ion batteries over a wide operating range. Therefore, in this paper a modified partial differential relationship is proposed as presented in Equation (7), where the Peukert constant is a function of the temperature, current ratio and cycle life. As we can observe in Equation (7), the capacity recovery as we have seen before has been taken into account:

$$
C_{d i s, I, t^{\circ}, D o D}=\left[\frac{\partial C_{d i s}}{\partial I_{d i s}} C_{d i s, I \text { dis }}+\frac{\partial C_{d i s}}{\partial t^{\circ}} C_{d i s, t^{\circ}}+\frac{\partial C_{d i s}}{\partial D o D} C_{d i s, D o D}\right] \cdot \mathrm{I}_{\text {dis }}^{\left(\frac{\partial k}{\partial I_{d i s}} k_{\text {ratio }} k_{\text {dis }}{ }_{\text {ratio }}+\frac{\partial k}{\partial t^{\circ}} \kappa_{t}^{\circ}+\frac{\partial k}{\partial L C} k_{L C}\right)}+C_{r e c}
$$


with:

$$
C_{r e c}=\left[\frac{\partial C_{r e c}}{\partial I_{d i s}} C_{r e c, I}+\frac{\partial C_{r e c}}{\partial t^{\circ}} C_{r e c, t^{\circ}}+\frac{\partial C_{r e c}}{\partial T_{r e s t}} C_{r e c, T_{r e s t}}\right]
$$

Figure 20. Peukert number evolution in function of cycle life at $40{ }^{\circ} \mathrm{C}$ working temperature for LFP battery.

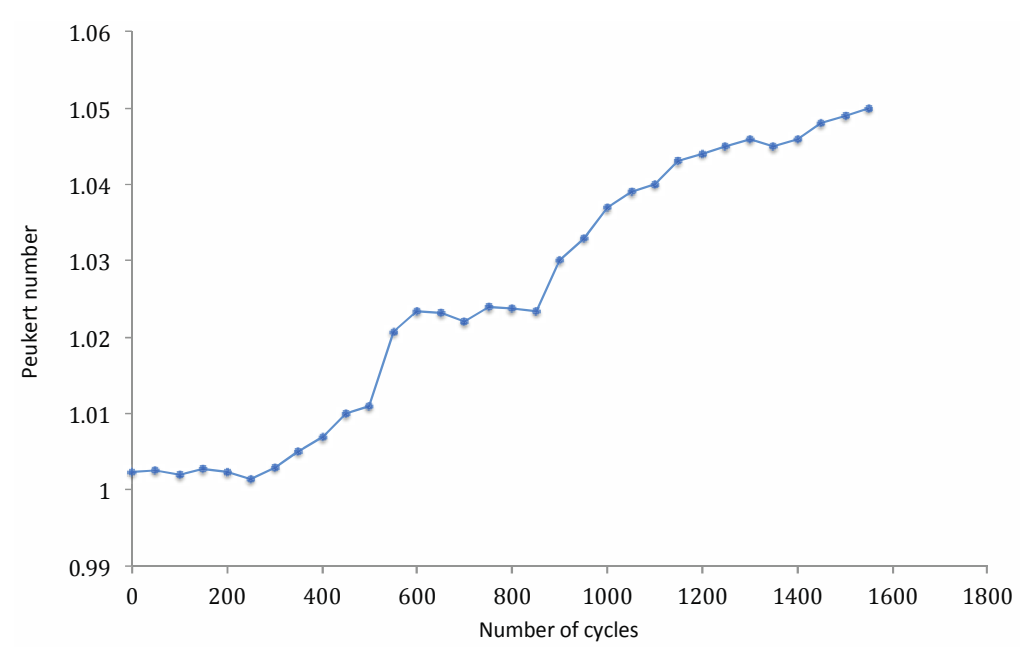

The new relationship contains all the parameters which affect the battery behavior under all conditions. However, the calculation based on this method becomes more complicated and more test results are required to enable evaluating the battery characteristics based on this relationship.

\section{Conclusions}

SoC estimation of batteries based on the Ampère-hour counting is an interesting methodology. However, it depends on many parameters such as applied current rate, ambient temperature, cycle life, depth of discharge and the Peukert constant.

In this paper, an extensive investigation on the main parameters that affect the discharge capacity of several lithium-ion chemistries has been proposed. From the analysis, it has been shown that the Peukert relationship is not sufficient to accurately predict the battery discharge capacity.

The Peukert constant depends of many relationships. In this paper, a modified Peukert relationship that includes all the parameters that are affecting discharge capacity of a battery has been introduced. Here it should be emphasized that the implementation of the modified Peukert relationship is more difficult and cumbersome for practical applications due to the high number of the correlations, which are required for an accurate estimation of the battery discharge capacity, and due to the complexity of the formula.

\section{Conflicts of Interest}

The authors declare no conflict of interest. 


\section{References}

1. International Energy Agency (IEA). Energy Technology Perspectives-Scenarios and Strategies to 2050; OECD Publishing: Paris, France, 2010.

2. Van Mierlo, J.; Maggetto, G. Comparison of the environmental damage caused by vehicles with different alternative fuel and drive trains in a Brussels context. J. Automob. Eng. 2003, 217, 583-593.

3. Boureima, F.S. Environmental Assessment of Conventional and Alternative Vehicles and Fuels in a Belgian Context. Ph.D. Thesis, Vrije Universiteit Brussel, Brussels, Belgium, 2011.

4. Axsen, J.; Kurani, K.S.; Burke, A. Are batteries ready for plug-in hybrid buyers? J. Transp. Policy 2008, 7, 173-182.

5. Van den Bossche, P.; Vergels, F.; van Mierlo, J.; Matheys, J.; van Autenboer, W. Subat: An assessment of sustainable battery technology. J. Power Sources 2006, 162, 913-919.

6. Coleman, M.; Lee, C.K.; Zhu, C.; Hurley, W.G. State-of-charge determination from EMF voltage estimation: Using impedance, terminal voltage, and current for lead-acid and lithium-ion batteries. IEEE Trans. Ind. Electron. 2007, 54, 2550-2557.

7. Omar, N.; Daowd, M.; van den Bossche, P.; Hegazy, O.; Smekens, J.; Coosemans, T.; van Mierlo, J. Rechargeable energy storage systems for plug-in hybrid electric vehicles-Assessment of electrical characteristics. Energies 2012, 5, 2952-2988.

8. Verbrugge, M.; Tate, E. Adaptive state of charge algorithm for nickel metal hydride batteries including hysteresis phenomena. J. Power Sources 2004, 126, 236-249.

9. Piller, S.; Perrin, M.; Jossen, A. Method for state of charge determination and their applications. J. Power Sources 2001, 96, 113-120.

10. Huet, F. A review of impedance measurements for determination of the state-of-charge or state-of-health of secondary batteries. J. Power Sources 1998, 70, 59-69.

11. Rodrigues, S.; Munichandraiah, N.; Shukla, A.K. A review of state-of-charge indication of batteries by means of a.c. impedance measurements. J. Power Sources 2000, 87, 12-20.

12. Hu, C.; Youn, B.D.; Chung, J. A multiscale framework with extended Kalman filter for lithium-ion battery SOC and capacity estimation. Appl. Energy 2012, 92, 694-704.

13. He, H.; Xiong, R.; Fan, J. Evaluation of lithium-ion battery equivalent circuit models for state of charge estimation by an experimental approach. Energies 2011, 4, 582-598.

14. Blanke, H.; Bohlen, O.; Buller, S.; de Doncker, R.W.; Fricke, B.; Hammouche, A.; Linzen, D.; Thele, M.; Sauer, D.U. Impedance measurements on lead-acid batteries for state-of-charge, state-of-health and cranking capability prognosis in electric and hybrid electric vehicles. J. Power Sources 2005, 144, 418-425.

15. He, Y.; Liu, X.T.; Zhang, C.B.; Chen, Z.H. A new model for State-of-Charge (SOC) estimation for high-power Li-ion batteries. Appl. Energy 2013, 101, 808-814.

16. Han, J.; Kim, D.; Sunwoo, M. State-of-charge estimation of lead-acid batteries using an adaptive extended Kalman filter. J. Power Sources 2009, 188, 606-612.

17. He, H.; Zhang, X.; Xiong, R.; Xu, Y.; Guo, H. Online model-based estimation of state-of-charge and open-circuit voltage of lithium-ion batteries in electric vehicles. Energy 2012, 39, 310-318.

18. He, W.; Williard, N.; Chen, C.; Pecht, M. State of charge estimation for electric vehicles batteries using unscented kalman filtering. Microelectron. Reliab. 2013, 53, 840-847. 
19. Cho, S.; Jeong, H.; Han, C.; Jin, S.; Lim, J.H.; Oh, J. State-of-charge estimation for lithium-ion batteries under various operating conditions using an equivalent circuit model. Comput. Chem. Eng. 2012, 41, 1-9.

20. Wu, G.; Lu, R.; Zhu, C.; Chan, C.C. An Improved Ampere-Hour Method for Battery State of Charge Estimation Based on Temperature, Coulomb Efficiency Model and Capacity Loss Model. In Proceedings of the IEEE Vehicle Power and Propulsion Conference (VPPC), Lille, France, 1-3 September 2010; pp. 1-4.

21. Peukert, W. Über die Abhänigkeit der Kapazität von der Entladestromstärke bei Bleiakkumulatoren. Elektrotechnisch Z. 1897, 27, 287-288 (in German).

22. IEC 61434: Secondary Cells and Batteries Containing Alkaline or Other Non-Acid Electrolytes-Guide to the Designation of Current in Alkaline Secondary Cells and Battery Standards. Available online: http://webstore.iec.ch/webstore/webstore.nsf/Artnum_PK/21274 (accessed on 28 July 2013).

23. Doerfell, D.; Sharkh, S.A. A critical review of using the Peukert equation for determining the remaining capacity of lead-acid and lithium-ion batteries. J. Power Sources 2006, 155, 395-400.

24. Cugnet, M.G.; Dubarry, M.; Liaw, B.Y. Peukert's law of a lead-acid battery simulated by a mathematical model. ECS Trans. 2010, 25, 223-233.

25. PEC Corporation. Available online: http://www.peccorp.com/SBT0550-tabs-glance.html (accessed on 28 July 2013).

26. Omar, N.; Daowd, M.; Hegazy, O.; Al Sakka, M.; Coosemans, T.; van den Bossche, P.; van Mierlo, J. Assessment of lithium-ion capacitor for using in battery electric vehicle and hybrid electric vehicle applications. Electrochim. Acta 2012, 86, 305-315.

27. Sawai, K.; Yamato, R.; Ohzuku, T. Impedance on lithium-ion battery consisting of $\mathrm{Li}\left(\mathrm{Li}_{1 / 3} \mathrm{Ti}_{5 / 3}\right) \mathrm{O}_{4}$ and $\mathrm{LiCo}_{1 / 2} \mathrm{Ni}_{1 / 2} \mathrm{O}_{2}$. J. Electrochem. 2005, 51, 1651-1655.

(C) 2013 by the authors; licensee MDPI, Basel, Switzerland. This article is an open access article distributed under the terms and conditions of the Creative Commons Attribution license (http://creativecommons.org/licenses/by/3.0/). 